\section{The Effect of Biological Factors on Birth Weight and Gestation in South Indian New-Borns}

\section{Grace Lalana Christopher}

Grace Specialist Clinic, India

*Corresponding author: Grace Lalana Christopher, Grace Specialist Clinic, India, Tel: 91 99728229403; E-mail: drgrace80@yahoo.com

Received date: April 03, 2017; Accepted date: April 26, 2018; Published date: May 03, 2018

Copyright: (c) 2018 Christopher GL. This is an open-access article distributed under the terms of the Creative Commons Attribution License, which permits unrestricted use, distribution, and reproduction in any medium, provided the original author and source are credited.

\begin{abstract}
Background: Understanding the effect of biological factors on birth weight of new-borns has public health importance because these indicators are associated with infant health and survival and influence development and health in later life.

Aim: The study was undertaken to determine the birth weight and gestational age characteristics in south Indian babies and correlated to biological factors.

Settings and design: A retrospective study of consecutive singleton live births, who delivered in the hospital in a metropolitan city of Bangalore, South India.

Materials and methods: A cohort of singleton live births, born from January 2015 to May 2017 were analysed to determine the mean birth weight and gestation and influence of various biological factors such as gender of baby, birth order, mother's age, obstetric complication such as PIH and Diabetes etc.

Results: Among a total of 2789 singleton live births, the mean birth weight was $2873.73 \pm 498.6 \mathrm{~g}$, mean gestation was $38.2 \pm 2$ weeks and Low Birth Weight (LBW) $<2500 \mathrm{~g}$ was $19.1 \%$. The Term, male, later births, older mothers above 30 years and pregnancy of Pregnancy Induced Hypertension $(\mathrm{PIH})$ and diabetes were associated with statistically significant higher birth weight $P=0.001, P=0.002, P=0.0001, P=0.001, P=0.0006$ and $P=0.0001$, respectively.

Conclusion: The mean birth weight and gestation for singleton live births in South India were determined, as well as the statistically significant impact of various biological criteria.
\end{abstract}

Keywords: Birth weight; Gestation; Biological factors

\section{Aim} of:

This is a retrospective study. The study was carried out with an aim

- Estimation of birth weight and gestational age of new-born confirmed by ultrasonogram undertaken within 18-20 weeks in singleton live term new-borns in order to obtain a standard birth weight and gestation reference range for Bangalore, South India

- Comparison of average birth weight of male and female babies

- Estimation of average birth weight in firstborn and that of later born babies

- Effect of other biological factors such as mother's age and complications of pregnancy such as PIH and Diabetes on birth weight and gestation

- Comparison of the above mentioned statistics with available national and other regional studies.

\section{Introduction}

Birth weight is one of the most important factors that predict the survival, future development and growth pattern of a new-born baby
[1-5]. Birth weight is mainly influenced by duration of gestation but other biological factors such as gender, birth order, mother's age, obstetric complications etc. also play a role. The present study was undertaken in a Speciality hospital in Bangalore, South India to determine the average birth weight and gestation as well the positive correlation of biological factors including complications of pregnancy such as PIH and Diabetes.

\section{Materials and Method}

All 2789 singleton live born babies included in this study among a total 2808 consecutive births from January 2015 to May 2017, at Shifaa Hospital, a multispecialty center catering mainly to the middle and lower socioeconomic strata, in the metropolitan city of Bangalore. Exclusion criteria were 19 twin deliveries and 18 stillbirths. All women received adequate prenatal care and gestational age assessed by Last Menstrual Period (LMP) correlated with Crown-rump length (CRL) measurement by ultrasound examination undertaken within 18-20 weeks to establish fetal age when menstrual dates were unknown or in pregnancies with discrepancy greater than \pm 7 days. If CRL and menstrual dates agreed to within the normal range of error ( \pm 7 days), then LMP was used to establish fetal age. 
Citation: Christopher GL (2018) The Effect of Biological Factors on Birth Weight and Gestation in South Indian New-Borns. J Pediatr Neurol Med

Page 2 of 5

Birth weight was recorded within $24 \mathrm{~h}$ of birth on a digital weighing machine accurate up to $10 \mathrm{~g}$. Sources of data were Labor room register, new-born register and maternal and neonatal records when required. Data was entered into EPIDATA entry software, 3.1.2701.2008 and data analysis with statistical significance was done using STATA version 13.1.

\section{Results}

There were a total of 2808 deliveries during the 29 month period from 1st Jan 2015 to 31st May 2017, exclusion criteria were 19 twin deliveries and 18 stillbirths. Among the 2789 singleton live births included in the study, birth weight was missing for $2.9 \%(\mathrm{n}=81)$, gestation was missing for $8.9 \%(n=251)$, gender was missing for $3.7 \%$ $(\mathrm{n}=105)$, birth order was missing for $4.1 \%(\mathrm{n}=116)$ and mother's age was missing for $7.3 \%(n=206)$.

Infants with normal birth weight (NBW) $\geq 2500$ g comprised $80.9 \%$ $(\mathrm{n}=2191)$ among which infants weighing 2500-3999 g comprised
$79.8 \%(\mathrm{n}=2163)$, of whom $38.1 \%(\mathrm{n}=1032)$ weighed $2500-2999 \mathrm{~g}$, $34.1 \%(\mathrm{n}=936)$ weighed $3000-3499 \mathrm{~g}$ and $7.2 \%(\mathrm{n}=195)$ weighed 3500-3999 g. NBW 2500-3999 g had mean gestation of $38.7 \pm 1.2$ weeks, High birth weight (HBW) $\geq 4000$ g comprising $1 \%(n=28)$ had mean gestation of $39.1 \pm 1.2$. This difference was not statistically significant (NS). However mean gestation in LBW $<2500$ g $37.1 \pm 2.3$ and NBW $\geq 2500 \mathrm{~g}$ being $38.7 \pm 1.2$ weeks was statistically significant $(\mathrm{P}<0.0001)$.

Term new-borns $\geq 37$ weeks comprised $88.3 \%(n=2243)$ and preterm $<37$ weeks was $11.6 \%(n=295)$. There were no post term births beyond 42 weeks. The mean birth weight for term and preterm babies was $2938 \pm 442 \mathrm{~g}$ and $2330 \pm 585 \mathrm{~g}$, respectively, a difference of $608 \mathrm{~g}$ being highly statistically significant $(\mathrm{P}=0.0001)$. Most term infants $39 \%$ $(\mathrm{n}=875)$ weighed $2500-2999 \mathrm{~g}$ contrasted with preterm $36.6 \%(\mathrm{n}=108)$ weighing less between $2000-2499 \mathrm{~g}$.

\begin{tabular}{|c|c|c|c|c|c|c|c|c|c|c|c|c|}
\hline \multirow{2}{*}{\multicolumn{2}{|c|}{ Criteria }} & \multicolumn{9}{|c|}{ Birth weight in grams (g) } & \multirow[b]{2}{*}{$\begin{array}{c}\text { Mean Birth Wt. (g) } \pm \\
\text { S.D. }\end{array}$} & \multirow[b]{2}{*}{$P$ Value } \\
\hline & & $\leq 999$ & $\begin{array}{c}1000-149 \\
9\end{array}$ & $\begin{array}{c}1500-199 \\
9\end{array}$ & $\begin{array}{c}2000-249 \\
9\end{array}$ & $\begin{array}{c}2500-299 \\
9\end{array}$ & $\begin{array}{c}3000-349 \\
9\end{array}$ & $\begin{array}{c}3500-399 \\
9\end{array}$ & $>4000$ & Total & & \\
\hline \multicolumn{2}{|c|}{ Singleton births } & 15 & 30 & 61 & 411 & 1032 & 936 & 195 & 28 & 2708 & $2873 \pm 498$ & \\
\hline Gestation & $<37$ & 7 & 21 & 39 & 108 & 83 & 31 & 6 & 0 & $295(11.6)$ & $2330 \pm 585$ & \multirow{2}{*}{$\begin{array}{c}P=0.000 \\
1\end{array}$} \\
\hline In weeks & $>37$ & 8 & 9 & 18 & 283 & 875 & 852 & 174 & 24 & $\begin{array}{l}2243 \\
(88.3)\end{array}$ & $2938 \pm 442$ & \\
\hline \multirow{2}{*}{ Sex } & Male & 4 & 15 & 29 & 182 & 480 & 506 & 115 & 19 & $\begin{array}{l}1350 \\
(50.3)\end{array}$ & $2916 \pm 501$ & \multirow{2}{*}{$\begin{array}{c}P=0.000 \\
2\end{array}$} \\
\hline & Female & 8 & 13 & 32 & 225 & 548 & 421 & 78 & 9 & $\begin{array}{l}1334 \\
(49.7)\end{array}$ & $2835 \pm 481$ & \\
\hline \multirow{2}{*}{ Birth Order } & First Born & 3 & 10 & 28 & 155 & 365 & 257 & 52 & 6 & $876(32.7)$ & $2817 \pm 484$ & \multirow{2}{*}{$\begin{array}{c}\mathrm{P}=0.000 \\
1\end{array}$} \\
\hline & Later Born & 12 & 20 & 32 & 252 & 648 & 672 & 139 & 22 & $\begin{array}{l}1797 \\
(67.2)\end{array}$ & $2899 \pm 503$ & \\
\hline \multirow{2}{*}{$\begin{array}{c}\text { Mother's Age/ } \\
\text { year }\end{array}$} & $<30$ & 13 & 23 & 50 & 335 & 829 & 722 & 143 & 15 & $\begin{array}{l}2129 \\
(82.4)\end{array}$ & $2857 \pm 492$ & \multirow{2}{*}{$P=0.001$} \\
\hline & $>30$ & 2 & 6 & 8 & 56 & 159 & 172 & 41 & 10 & $454(17.5)$ & $2941 \pm 509$ & \\
\hline \multirow{3}{*}{$\begin{array}{l}\text { Mode of } \\
\text { Delivery }\end{array}$} & Normal & 9 & 17 & 32 & 222 & 566 & 505 & 76 & 8 & $\begin{array}{c}1435 \\
(52.9)\end{array}$ & \multirow{2}{*}{$2848 \pm 477$} & \multirow{3}{*}{ NS } \\
\hline & $\begin{array}{l}\text { Elective } \\
\text { LSCS }\end{array}$ & 1 & 3 & 5 & 50 & 160 & 135 & 36 & 8 & $398(14.6)$ & & \\
\hline & $\begin{array}{l}\text { Emergen } \\
\text { LSCS }\end{array}$ & 5 & 10 & 24 & 125 & 257 & 237 & 72 & 9 & 739 (27.3) & $2850 \pm 529$ & \\
\hline \multirow{2}{*}{$\mathrm{PIH}$} & Yes & 2 & 5 & 9 & 27 & 36 & 44 & 13 & 0 & $136(5.0)$ & $2730 \pm 511$ & \multirow{2}{*}{$\begin{array}{c}P=0.000 \\
6\end{array}$} \\
\hline & No & 13 & 25 & 52 & 385 & 996 & 891 & 182 & 28 & $\begin{array}{l}2572 \\
(95.0)\end{array}$ & $2881 \pm 496$ & \\
\hline \multirow{2}{*}{ Diabetes } & Yes & 0 & 2 & 0 & 14 & 41 & 44 & 19 & 4 & $124(4.6)$ & $3039 \pm 553$ & \multirow{2}{*}{$\begin{array}{c}P=0.000 \\
1\end{array}$} \\
\hline & No & 15 & 28 & 61 & 398 & 991 & 892 & 175 & 24 & $\begin{array}{l}2584 \\
(95.4)\end{array}$ & $2853 \pm 515$ & \\
\hline
\end{tabular}

Table 1: Distribution of birth weight in relation to biological criteria. 
Page 3 of 5

Sex ratio revealed 984 females to 1000 male infants. However more nearly half of male babies $47.4 \%(\mathrm{n}=640)$ weighed $\geq 3000 \mathrm{~g}$ when compared to about one-third female babies $38.4 \%(\mathrm{n}=508)$. The mean birth weight for male and female was $2916 \pm 501 \mathrm{~g}$ and $2835 \pm 481 \mathrm{~g}$ respectively, a difference of $81 \mathrm{~g}$ being statistically significant $(\mathrm{P}<0.0001)$. However slightly more males $12.6 \% \quad(\mathrm{n}=160)$ were premature $<37$ weeks compared to females $10.3 \%(n=130)$. The mean gestation for male and female was $38.3 \pm 1.7$ and $38.4 \pm 1.6$ weeks, respectively, was statistically significant $(\mathrm{P}=0.02)$ as shown in Tables 1 and 2 .

First birth infants comprised $32.7(\mathrm{n}=876)$, while second and later births comprised two-thirds $67.2 \% \quad(\mathrm{n}=1797)$. However $37.7 \%$ $(\mathrm{n}=1797)$ of later births weighed more 3000-3499 g, compared to $41.6 \%(n=876)$ first birth infants who weighed less $2500-2999 \mathrm{~g}$. The mean birth weight for first and later birth infants was $2817 \pm 484 \mathrm{~g}$ and $2899 \pm 503 \mathrm{~g}$, respectively, a difference of $82 \mathrm{~g}$ being highly statistically significant $(\mathrm{P}=0.0001)$. Prematurity was low $8.9 \%(\mathrm{n}=75)$ in first births compared to12.8\% $(n=220)$ of later births. The mean gestation in first and later birth infants was $38.5 \pm 1.5$ and $38.2 \pm 1.6$ weeks, respectively, the difference being statistically significant $(\mathrm{P}<0.001)$.

Teenage mothers, 19 years and below comprised $8.5 \%(\mathrm{n}=220)$, majority $39.1 \%(n=1012)$ were $20-24$ years and $34.7 \%(n=897)$ between 25-29 years, thus nearly three fourth 73.8 percent of mothers were in their twenties $20-29$ years, $14.4 \%(\mathrm{n}=373)$ older mothers $30-34$ years comprised and $3.1 \%(\mathrm{n}=81)$ were above 35 years. Hence majority $82.4 \%(\mathrm{n}=2129)$ were young mothers below 30 years and $17.5 \%$ $(n=454)$ were 30 years and above.

\begin{tabular}{|c|c|c|c|c|c|c|c|}
\hline \multirow{2}{*}{\multicolumn{2}{|c|}{ Criteria }} & \multicolumn{4}{|c|}{ Gestational Age in weeks } & \multirow{2}{*}{ Mean Gestation in weeks \pm S.D. } & \multirow{2}{*}{ P Value } \\
\hline & & \multirow{2}{*}{$\begin{array}{c}<37 \\
295(11.6 \%)\end{array}$} & \multirow{2}{*}{$\begin{array}{c}37-40 \\
1696(66.8)\end{array}$} & \multirow{2}{*}{$\begin{array}{c}\mathbf{4 0 +} \\
274(10.8)\end{array}$} & \multirow{2}{*}{$\begin{array}{c}\text { Total } \\
2538(100)\end{array}$} & & \\
\hline No. of births & & & & & & $38.2 \pm 2$ & \\
\hline VLBW & $<1500 \mathrm{~g}$ & $28(62.2)$ & $13(28.8)$ & $4(8.8)$ & $45(1.77)$ & $33.7 \pm 4.2$ & \multirow{2}{*}{$P<0.001$} \\
\hline LBW & $1500-2500 \mathrm{~g}$ & $147(32.8)$ & $285(63.6)$ & $16(3.5)$ & $448(17.6)$ & $37.3 \pm 1.8$ & \\
\hline NBW & $2500-4000 \mathrm{~g}$ & $120(5.9)$ & $1653(81.8)$ & $248(12.27)$ & $2021(79.6)$ & $38.7 \pm 1.2$ & \\
\hline HBW & $\geq 4000 \mathrm{~g}$ & 0 & $18(75)$ & $6(25)$ & $24(0.94)$ & $39.1 \pm 1.2$ & \\
\hline \multirow{2}{*}{ Sex } & Male & $160(12.6)$ & $982(77.5)$ & $125(9.86)$ & $1267(50.1)$ & $38.3 \pm 1.7$ & \multirow{2}{*}{$P=0.02$} \\
\hline & Female & $130(10.3)$ & $984(78.0)$ & $147(11.6)$ & $1261(49.9)$ & $38.4 \pm 1.6$ & \\
\hline \multirow{2}{*}{ Birth Order } & First Born & $75(8.9)$ & $645(77.2)$ & $115(13.7)$ & $835(32.8)$ & $38.5 \pm 1.5$ & \multirow{2}{*}{$P<0.001$} \\
\hline & Later Born & $220(12.8)$ & $1334(77.9)$ & $157(9.1)$ & $1711(67.2)$ & $38.2 \pm 1.6$ & \\
\hline \multirow{2}{*}{ Mother's Age } & $\leq 30$ years & $238(9.6)$ & $1572(75.1)$ & $229(11.2)$ & $2039(82.7)$ & $38.4 \pm 1.6$ & \multirow{2}{*}{$P=0.005$} \\
\hline & $>30$ years & $79(11.5)$ & $343(80.7)$ & $33(7.7)$ & $425(17.2)$ & $38.1 \pm 1.5$ & \\
\hline \multirow{3}{*}{ Mode of Delivery } & Normal & $132(9.8)$ & $1062(77.8)$ & $170(12.4)$ & $1364(56.1)$ & $38.5 \pm 1.6$ & \multirow{3}{*}{$P<0.001$} \\
\hline & Elective LSCS & $43(11.4)$ & $314(83.5)$ & $19(5.0)$ & $376(35.2)$ & $38.1 \pm 1.3$ & \\
\hline & Emergency LSCS & $114(16.5)$ & $510(73.9)$ & $66(9.5)$ & $690(64.7)$ & $38.1 \pm 1.8$ & \\
\hline \multirow{2}{*}{$\mathrm{PIH}$} & Yes & $33(24.8)$ & $90(67.7)$ & $10(7.5)$ & $133(5.1)$ & $37.5 \pm 2.0$ & \multirow{2}{*}{$P<0.001$} \\
\hline & No & $263(10.8)$ & 1902 (78.3) & 265 (10.9) & $2430(94.8)$ & $38.4 \pm 1.6$ & \\
\hline \multirow{2}{*}{ Diabetes } & Yes & 27 (21.9) & $93(75.6)$ & $3(2.4)$ & $123(4.8)$ & $37.7 \pm 1.4$ & \multirow{2}{*}{$P<0.001$} \\
\hline & No & 269 (11) & $1899(77.8)$ & $272(11.1)$ & 2440 (95.2) & $38.4 \pm 1.6$ & \\
\hline
\end{tabular}

Table 2: Gestational age characteristics of new-borns $<37$ weeks, 37-40 weeks and 40+ weeks.

Most 38.9\% ( $\mathrm{n}=826)$ infants of young mothers below 30 years weighed 2500-2999 $\mathrm{g}$ while $37.8 \%(\mathrm{n}=172)$ infants of older mothers $\geq$ 30 years weighed more $3000-3499 \mathrm{~g}$. The mean birth weight in young mothers below 30 years was $2857 \pm 492 \mathrm{~g}$ compared to $2941 \pm 509 \mathrm{~g}$ for older mothers, difference of $84 \mathrm{~g}$ was highly statistically significant $(\mathrm{P}=0.001)$. However older mothers $\geq 30$ years had higher incidence of prematurity $11.5 \%(n=79)$ compared to $9.6 \%(n=238)$ in younger mothers, and mean gestation of $38.1 \pm 1.5$ and $38.4 \pm 1.9$ weeks respectively was statistically significant $(\mathrm{P}=0.005)$.
Another variable of mode of delivery, normal vertex vaginal delivery occurred in half $53.2 \%(\mathrm{n}=1364)$ followed by Caesarean Sections (C.S.) in $41.6 \%(n=1066)$, Vacuum extractions 3.5\% $(n=97)$ and Low Perineal Forceps (LPF) delivery $1.4 \%(\mathrm{n}=39)$. Breech presentation occurred in $2.5 \%(n=50)$, but only $0.5 \%(n=10)$ were assisted vaginal breech delivery and remaining $1.5 \%$ (40) by emergency C.S. However among a total 1066 C.S, most $64.7 \%(\mathrm{n}=690)$ were emergency C.S and $35.2 \%$ $(\mathrm{n}=376)$ elective or planned C.S. Repeat C.S. were performed in one third $32.6 \%(\mathrm{n}=348)$. The mean birth weight for normal deliveries was $2831 \pm 477 \mathrm{~g}$ and C.S. $2850 \pm 529 \mathrm{~g}$, difference of $19 \mathrm{~g}$ being 
statistically significant $(\mathrm{P}=0.047)$. Incidence of prematurity was higher $16.5 \%(n=114)$ in emergency C.S. compared to $11.4 \%(n=43)$ in elective C.S. The mean gestation for emergency C.S. and elective C.S. was $38.1 \pm 1.3$ and $38.1 \pm 1.8$ weeks respectively was not significant (NS) $(\mathrm{P}=0.94)$. However the mean gestation in infants delivered normally compared to overall C.S. was $38.5 \pm 1.6$ and $38.1 \pm 1.8$ weeks respectively being statistically significant $(\mathrm{P}<0.001)$.

The incidence of obstetric complications of Pregnancy Induced Hypertension (PIH) was $5 \%(n=136)$ and Diabetes $4.6 \%(n=124)$. Most infants $32.3 \%(\mathrm{n}=44)$ with obstetrical complications of $\mathrm{PIH}$ and $35.4 \%$ $(\mathrm{n}=44)$ with maternal diabetes weighed between 3000-3499g. The mean birth weight with and without PIH complicating pregnancy was $2730 \pm 511 \mathrm{~g}$ and $2881 \pm 496 \mathrm{~g}$, respectively, the difference of $151 \mathrm{~g}$ being highly statistically significant $(\mathrm{P}=0.0006)$. However infants of diabetic mothers weighed more, mean birth weight $3039 \pm 455 \mathrm{~g}$ compared to $2853 \pm 515 \mathrm{~g}$ in non-diabetic mothers, a difference of 186 g, was highly statistically significant $(\mathrm{P}=0.0001)$.

Incidence of prematurity was high $24.8 \%(\mathrm{n}=33 /$ total 136$)$ with $\mathrm{PIH}$ complicating pregnancy compared to $21.9 \%(n=27 /$ total 124$)$ infants of diabetic mothers who had low mean gestation of $37.5 \pm 2.0$ and $37.7 \pm$ 1.4 weeks, respectively compared to $38.4 \pm 1.6$ in uncomplicated pregnancy being statistically significant $(\mathrm{P}<0.001)$.

\section{Discussion}

In this study 2789 singleton live births, had mean birth weight of $2873.73 \pm 498.6 \mathrm{~g}$, mean gestation $38.2 \pm 2$ weeks and LBW $<2500 \mathrm{~g}$ $19.1 \%$. A study from North India also reported mean birth weight $2725.40 \pm 424.64 \mathrm{~g}$, mean gestation of $38.1 \pm 1.9$ weeks and LBW 19.8 $\%$ (4). Term infants $\geq 37$ weeks comprised $88.3 \%(n=2243)$ and $11.6 \%$ $(\mathrm{n}=295)$ preterm in present study compared to North India with $76.8 \%$ term and $23.2 \%$ preterm, respectively. (4). Mean birth weight for term $2938 \pm 442 \mathrm{~g}$ and preterm $2330 \pm 585 \mathrm{~g}$, difference of $608 \mathrm{~g}$ was statistically significant $(\mathrm{P}=0.0001)$. In the present study $\mathrm{VLBW}<1500 \mathrm{~g}$ comprised $1.6 \%$ had mean gestation of $33.7 \pm 4.2$ weeks as compared to LBW $1500-2499 \mathrm{~g}$ with $37.3 \pm 1.8$ weeks being statistically significant $(\mathrm{P}<0.001)$.

According to UNICEF LBW rates were $7 \%, 16 \%$ and $19 \%$, respectively in industrialized, developing and least developed countries [6]. LBW and preterm birth rates were $17.0 \%$ versus $5.5 \%$ and $12.3 \%$ versus 6.9\%, respectively in South India and Nova Scotia, Canada [7]. Unlike in Western countries, where the incidence of LGA babies has spiralled upward, it has remained nearly at the same level over one and a half decades, reported in South India, despite improvements in socioeconomic status and obstetric care, the mean birth weight $2846 \mathrm{~g}$ in 1996 remained at $2907 \mathrm{~g}$ in 2010 over 15 years, with a difference of only 61 grams $[5,7]$. Thus Indian women will continue to have a high incidence of LBW up to $27.4 \%$ reported in rural India [8] though it is unclear whether high rates of LBW in South Asia are due to poor fetal growth or short pregnancy duration [9]. In contrast western population report a high mean birth weight of $3446 \mathrm{~g}$ in U.S born white women, a difference of $573 \mathrm{~g}$ compared to the present study [10]. Globally of the 20 million LBW representing $15.5 \%$ of all births, $95.6 \%$ are in developing countries with India alone accounting for $40 \%$ LBW in developing countries [11], however in developing countries the majority of LBW new-borns have intrauterine growth restrictions rather than being born preterm [12] hence a redefinition of LBW is indicated in ethnic Asians so as to more accurately identify prematurity as cause of LBW [12].
Sex ratio was 984 females to 1000 male infants; a skewed 804 female/1000 male infants was reported from North India [4]. Male babies had higher mean birth weight of $2916 \pm 501$ compared to female babies with $2835 \pm 481$, difference of 81 g being highly statistically significant $(\mathrm{P}<0.0001)$, similarly also reported in another study male weighed $45 \mathrm{~g}$ more than female babies, mean birth weight being $2934 \mathrm{~g}$ and $2889 \mathrm{~g}$, respectively [4]. However more males $12.6 \%(\mathrm{n}=160)$ were born preterm $<37$ weeks, compared to females $10.3 \%(n=130)$. The mean gestation in males and females being $38.3 \pm 1.7$ and $38.4 \pm 1.6$ respectively also statistically significant $(\mathrm{P}=0.02)$.

First births were lighter with mean birth weight of $2817 \pm 484 \mathrm{~g}$ compared to $2899 \pm 503 \mathrm{~g}$ in later born infants, difference of $82 \mathrm{~g}$ being statistically significant $(\mathrm{P}=0.0001)$. However more $12.8 \%(\mathrm{n}=220)$ later births were preterm $<37$ weeks, compared to $8.9 \%(n=75)$ first birth infants, with a mean gestation of $38.2 \pm 1.6$ weeks and $38.5 \pm 1.5$ weeks, respectively being statistically significant $(\mathrm{P}<0.001)$. Other study also reported later birth infants being heavier by $100 \mathrm{~g}$ with the mean birth weight of $2880 \mathrm{~g}$ compared to $2770 \mathrm{~g}$ for first born babies [4].

Infants of young mothers 20-29 years had lower mean birth weight of $2857 \pm 492 \mathrm{~g}$ compared to $2941 \pm 509 \mathrm{~g}$ in older mothers $\geq 30$ years, a difference of $84 \mathrm{~g}$ being statistically significant $(\mathrm{P}=0.001)$. However older mothers $\geq 30$ years had higher incidence of prematurity $11.5 \%$ $(n=79)$ compared to $9.6 \%(n=238)$ infants born to younger mothers. The mean gestation for mothers $<30$ and $\geq 30$ years was $38.4 \pm 1$ and $38.1 \pm 1.5$ weeks, respectively being statistically significant $(\mathrm{P}=0.005)$.

Caesarean section rate increased to $41.6 \%$, majority being emergency section $64.7 \%$ and in $35.2 \%$ elective or planned sections. Repeat section was performed in one third $32.6 \%$. In contrast other studies report a low cesarean rate of $15.3 \%$ in North India [4] and $3.1 \%$ in 1986-87 increasing to $10.9 \%$ in $2004-2005$ in South India while in Nova Scotia, Canada it increased from $20.2 \%$ to $28.4 \%$ [5]. Understandably though emergency cesarean section delivery was related to a higher incidence of prematurity $16.5 \%$ compared to $11.4 \%$ among elective sections, the mean gestation between emergency and election sections was not statistically significant $(\mathrm{P}=0.94)$, contrasted with mean gestation of $38.5 \pm 1.6$ weeks in infants with normal delivery compared to $38.1 \pm 1.6$ C.S being statistically significant $(\mathrm{P}<0.001)$. in contrast infants of normal delivery had lower mean birth weight of $2848 \pm 477 \mathrm{~g}$ to $2850 \pm 529 \mathrm{~g}$ in caesarean births, difference of $19 \mathrm{~g}$ being statistically significant $(\mathrm{P}=0.047)$. A higher incidence of LBW $22.1 \%$ was noted for emergency sections compared to $14.8 \%$ in elective sections. Thus the risk for LBW and prematurity was higher with emergency sections.

Obstetric complications of PIH and Diabetes had higher incidence of prematurity $24.8 \%$ and $21.9 \%$, respectively with mean gestation of $37.5 \pm 2.0$ weeks and $37.7 \pm 1.4$ weeks respectively compared to $38.4 \pm$ 1.6 weeks in uncomplicated pregnancy of statistical significance $(\mathrm{P}<0.001)$. Similarly a low mean birth weight of $2730 \pm 511 \mathrm{~g}$ in infants with PIH complicating pregnancy contrasted with higher mean birth weight of $3039 \pm 455 \mathrm{~g}$ in infants of diabetic mothers, in contrast pregnancy uncomplicated with PIH and diabetes had mean birth weight of $2881 \pm 496$ and $2853 \pm 515 \mathrm{~g}$, respectively, this difference of $151 \mathrm{~g}$ and $186 \mathrm{~g}$, respectively being highly statistically significant $(\mathrm{P}=0.0006)$ in the former and $(\mathrm{P}<0.001)$ in the latter.

\section{Conclusion}

Mean birth weight is a good indicator for any population to determine outcome of new-borns. This study reveals that though 
Citation: Christopher GL (2018) The Effect of Biological Factors on Birth Weight and Gestation in South Indian New-Borns. J Pediatr Neurol Med

Page 5 of 5

duration of gestation had a major impact on birth weight other biological factors such as gender with male babies, second and later births, as well as infants born to older mothers tended to have statistically significantly higher mean birth weight. In contrast infants of mothers with PIH registered lower mean birth weight to infants of diabetic mothers with higher mean birth weight but significantly shortened gestation.

Mean birth weight is a good indicator for any population to determine outcome of new-borns. This study reveals that though duration of gestation had a major impact on birth weight other biological factors such as gender with male babies, second and later births, as well as infants born to older mothers tended to have statistically significantly higher mean birth weight. In contrast infants of mothers with PIH registered lower mean birth weight to infants of diabetic mothers with higher mean birth weight but significantly shortened gestation compared to uncomplicated pregnancy.

\section{Funding}

No External Funding.

\section{References}

1. Jadhav M, Christopher GL (1986) Perinatal mortality rates in Vellore, Part I. A study of 21,585 infants. Indian J Pediatr 53: 351-353.

2. Christopher GL, Jadhav M (1986) Perinatal mortality in Vellore Part II Lethal malformations. Indian J Pediatr 53: 353-357.
3. Wilcox A, Skjaeven R, Buekens P, Kiely J (1995) Birth weight and perinatal mortality. A comparison of the United States and Norway. JAMA 273: 709-711.

4. Kumar K, Chaudhary S (2010) Prasad maternal indicators and obstetric outcome in north India. A hospital-based study. J Postgrad Stud 56: 192-195.

5. George K, Prasad J, Singh D, Minz S, Albert DS, et al. (2009) Perinatal outcomes in a South Asian setting with high rates of low birth weight. BMC Pregnancy Childbirth 9: 5-10.

6. UNICEF. Low birth weight.

7. Kumar VS, Jeyaseelan L, Sebastian T, Regi A, Mathew J, et al. (2013) New birth weight reference standards customised to birth order and sex of babies from south India. BMC Pregnancy Childbirth 13:38.

8. Agarwal S, Agarwal A, Bansal AK, Agarwal DK, Agarwal KN (2002) Birth weight patterns in rural undernourished pregnant women. Indian Pediatr 39: 244-253.

9. Villar J, Belizán JM (1982) The relative contribution of prematurity and fetal growth retardation to low birth weight in developing and developed societies. Am J Obstet Gynecol 143: 793-798.

10. David RJ, Collins JW (1997) Differing birth weight among Infants of US born, blacks, African-born and US born whites. N Engl J Med 337: 1209-1214.

11. Kramer MS (1987) Determinants of low birth weight: Methodological assessment and meta-analysis. Bull World Health Organ 65: 663-737.

12. Christopher GL (2018) Low birth weight criteria in Ethnic Asian, Eurasian and Caucasian new-borns. Recent Adv Perinatol Spec Ref Ethnicity, pp: 253-257. 